DOI: $10.12731 / 2306-1561-2013-4-15$

\title{
NEW APPROACHES TO AUTOMATED SUPERVISORY SYSTEMS ROAD INDUSTRIAL ENTERPRISES
}

\section{Polgun M.B.}

\section{Abstract}

In was considered principles of work of modern automated dispatching enterprise automobile transport. It was considered main algorithms and approaches, after analyzing it was suggested new mechanism of enterprise products transportation planning. This mechanism is based on address databases, the warehouses of region infrastructure objects. So it was suggested methods of storing and input information in data base.

Keywords: dispatching control, transport, transportation, control points.

\section{УДК 656.025:681.3}

\section{НОВЫЕ ПОДХОДЫ К РАЗРАБОТКЕ АВТОМАТИЗИРОВАННЫХ СИСТЕМ ДИСПЕТЧЕРСКОГО УПРАВЛЕНИЯ ТРАНСПОРТОМ ПРОМЫШЛЕННОГО ПРЕДПРИЯТИЯ}

\section{Польгун М.Б.}

\section{Аннотация}

В статье рассмотрены принципы работы современных автоматизированных систем диспетчерского управления транспортом промышленного предприятия. Рассмотрены основные алгоритмы и подходы при работе таких систем. Выявлены основные недостатки, по результатам анализа которых предложен новый механизм построения планов перевозок продукции предприятий. Этот подход основан на адресных базах данных, хранилищах информации об инфраструктурных объектах местности. Также предложены способы хранения и наполнения базы данных.

Ключевые слова: диспетчерское управление, транспорт, транспортировка, контрольные пункты.

\section{Введение}

Важной составляющей успешной работы промышленного предприятия является своевременные, быстрые и бесперебойные сбыт и транспортировка произведенной продукции. Основная нагрузка при выполнении этой задачи возлагается на автомобильный транспорт, который является оптимальным с точки зрения множества факторов. Для качественной транспортировки предприятие необходимо учесть 
множество факторов, таких как расходы на транспортировку, своевременность доставки, постоянно меняющуюся дорожную обстановку.

В настоящее время широкое распространение для решения таких задач получили средства спутниковой навигации. Они широко применяются в области управления грузовыми и пассажирскими перевозками для обеспечения непрерывного мониторинга работы транспортных средств (ТС). Мониторинг процесса транспортировки продукции стал неотъемлемой частью всего процесса работы предприятия. Он позволяет достичь недоступных ранее возможностей в процессе планирования и работы предприятия, повысить эффективность и снизить издержки производства [1 - 20].

\section{Современные автоматизированные системы диспетчерского управления}

На базе средств спутниковой навигации строятся автоматизированные средства диспетчерского управления парком автомобильного транспорта (АСДУ). Основным назначение подобных систем является обеспечение надежности централизованного управления парком транспортных средств промышленного предприятия. АСДУ решает ряд задач $[1,5]$ :

1. Повышение качества планирования и исполнения запланированных транспортных работ, улучшение процесса транспортировки продукции предприятия;

2. Повышение эффективности использования транспортного средства (сокращение непроизвольных потерь времени на линии, рациональное использование подвижного состава и резерва и, как следствие, сокращение затрат на транспортное обслуживание);

3. Повышение безопасности функционирования автомобильного транспорта предприятия.

В основе функционирования подсистемы планирования перевозок современных диспетчерских систем лежит понятие контрольного пункта (КП) - некоторой области на местности, определяющей обязательный пункт прохождения транспортного средства (рисунок 1).

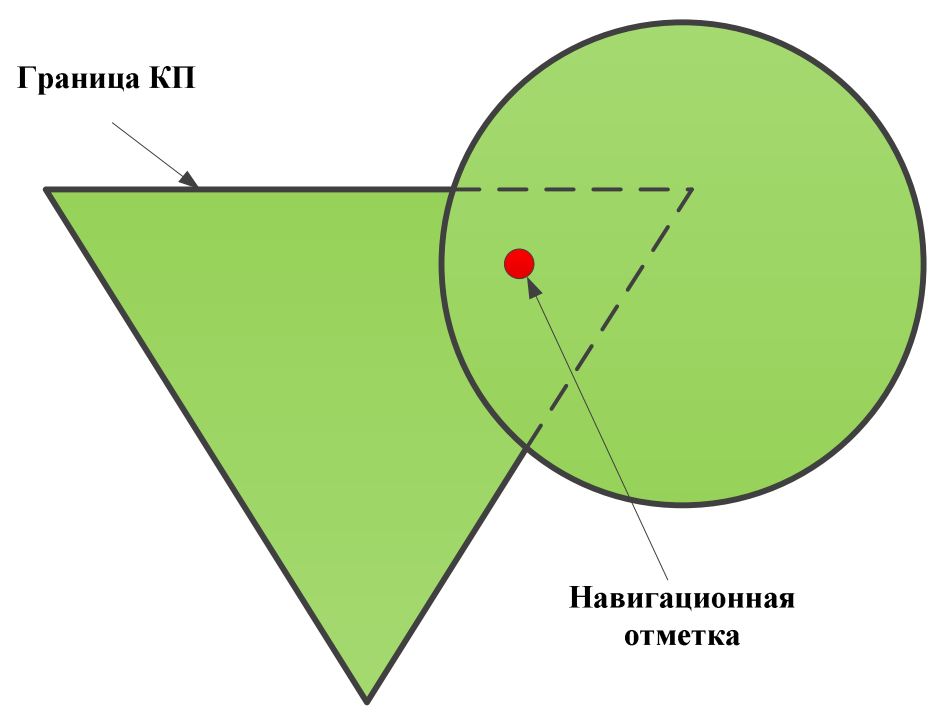

Рисунок 1 - Схема попадания навигационной отметки в КП 
КП используются для составления планов перевозок (в заданный период времени ТС должно пройти через заданный упорядоченный набор КП) и для определения фактических показателей движения ТС [1 - 20].

В виде КП можно представить различные реальные объекты инфраструктуры (объекты погрузки/разгрузки, налива/слива, строительства, АЗС и т. д.). При поступлении в АСДУ навигационной отметки от ТС проверяется ее вхождение в каждый из полигонов. Процесс определения КП, которому принадлежит навигационная отметка, называется «привязкой» навигационной отметки к КП [2]. КП может состоять из полигона, или из геометрических примитивов: треугольников, прямоугольников, параллелограммов, окружностей. Если КП состоит из нескольких примитивов, то его называют комплексный контрольный пункт. Зоной КП является зона объединения всех примитивов, составляющих КП.

Для определения попадания навигационной отметки в зону КП может использоваться «метод трассировки лучей» (Рисунок 2 - Алгоритм привязки навигационной отметки к КП). Этот алгоритм используется в вычислительной геометрии для определения попадания точки в замкнутый полигон, но он не учитывает погрешности, связанные с работой навигационного оборудования.

Этими погрешностями можно пренебречь, так как зоны контрольных пунктов редко бывают более 500 метров, и при таких размерах влияние искажения картографической проекции не будет вносить больших погрешностей [2].

В процессе работы АСДУ в системе помечаются КП, к которым были привязаны навигационными отметки. Это называется зачетом КП. Зачет показывает, какие КП были посещены ТС, а какие оказались «ложными». Подход основан на определении времени нахождения ТС в КП. Исходя из данных о зачтенных и ложных КП, АСДУ позволяет определять фактические показатели выполнения транспортной работы, а также сравнивать эти показатели с плановыми, которые были составлены до выпуска ТС на линию.

Использование КП хорошо зарекомендовало себя на протяжении долгого времени, но этот подход не лишен недостатков. Основными недостатками КП являются [4]:

- Ручной ввод. КП наносятся вручную специалистами диспетчерских центров предприятия. Этот процесс является трудоемким, монотонным и утомительным. Следовательно, работоспособность не лишена вредного влияния человеческого фактора.

- КП являются статичными. Они заносятся один раз в базу данных системы. Далее они могут актуализироваться или удаляться, но это происходит редко или вообще не происходит. Если рассмотреть систему, работающую в масштабах какого-либо региона или страны в целом (не говоря уже о предприятиях, участвующих в процессе международных перевозок), то такие данные в БД занимать огромные объемы, что влечет за собой медленную работу систему. 
- КП являются дискретными и обособленными. КП задает определенную область. Если транспортное средство по какой-либо причине прошло не через заданное КП, то это свидетельствует о нарушении плана перевозок, хотя это может быть и не так по ряду причин.

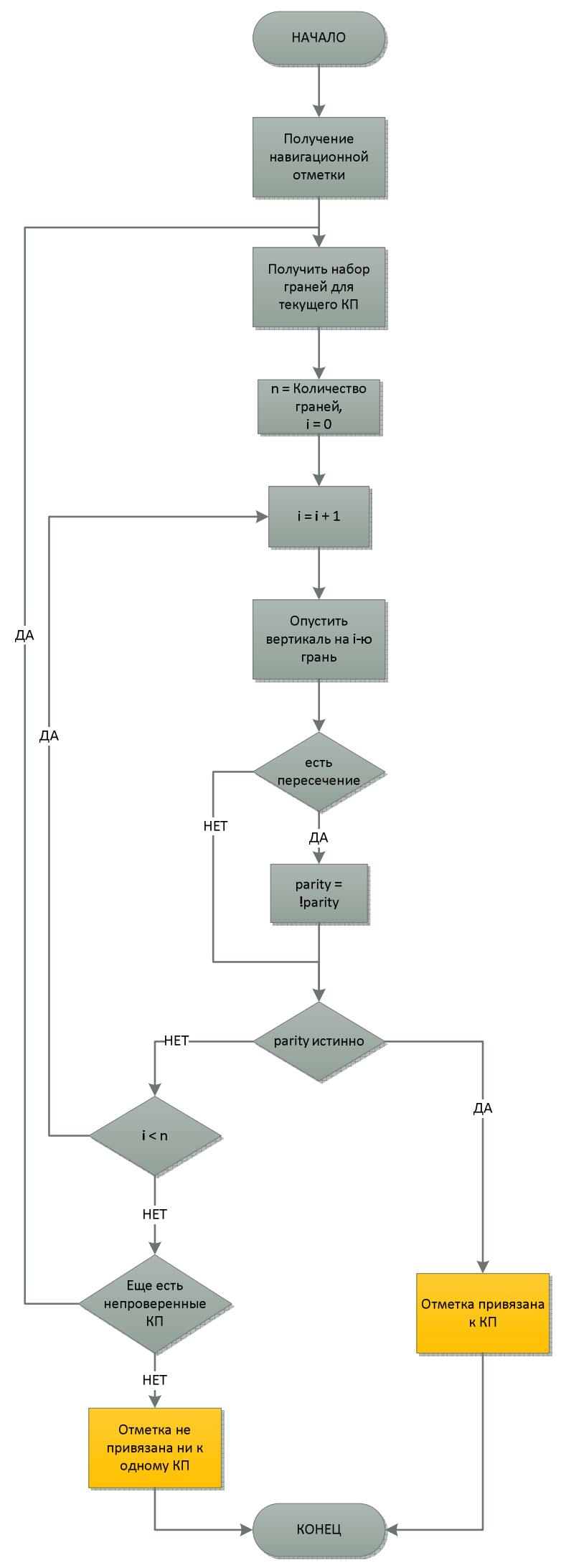




\section{Рисунок 2 - Алгоритм привязки навигационной отметки к КП}

Исходя из всех перечисленных выше замечаний, предлагается отойти от статического ручного составления плана транспортировок и перейти на автоматизированное динамическое составление планов. Это не означает, что влияние человека на систему будет исключено полностью. Это невозможно. Но влияние человеческого фактора будет минимизировано.

\section{Адресные базы данных}

Одним из способов решения поставленной задачи является применение адресной базы данных, в которых хранится набор точек и их описание. В такой базе данных можно задавать любые объекты инфраструктуры, необходимые предприятию, например объекты строительства, объекты погрузки/разгрузки, налива/слива, заправочные станции, парковочные площадки и многие другие. А в общем случае с таким же образом можно задавать города, улицы, трассы и другие географические объекты (рисунок 3).

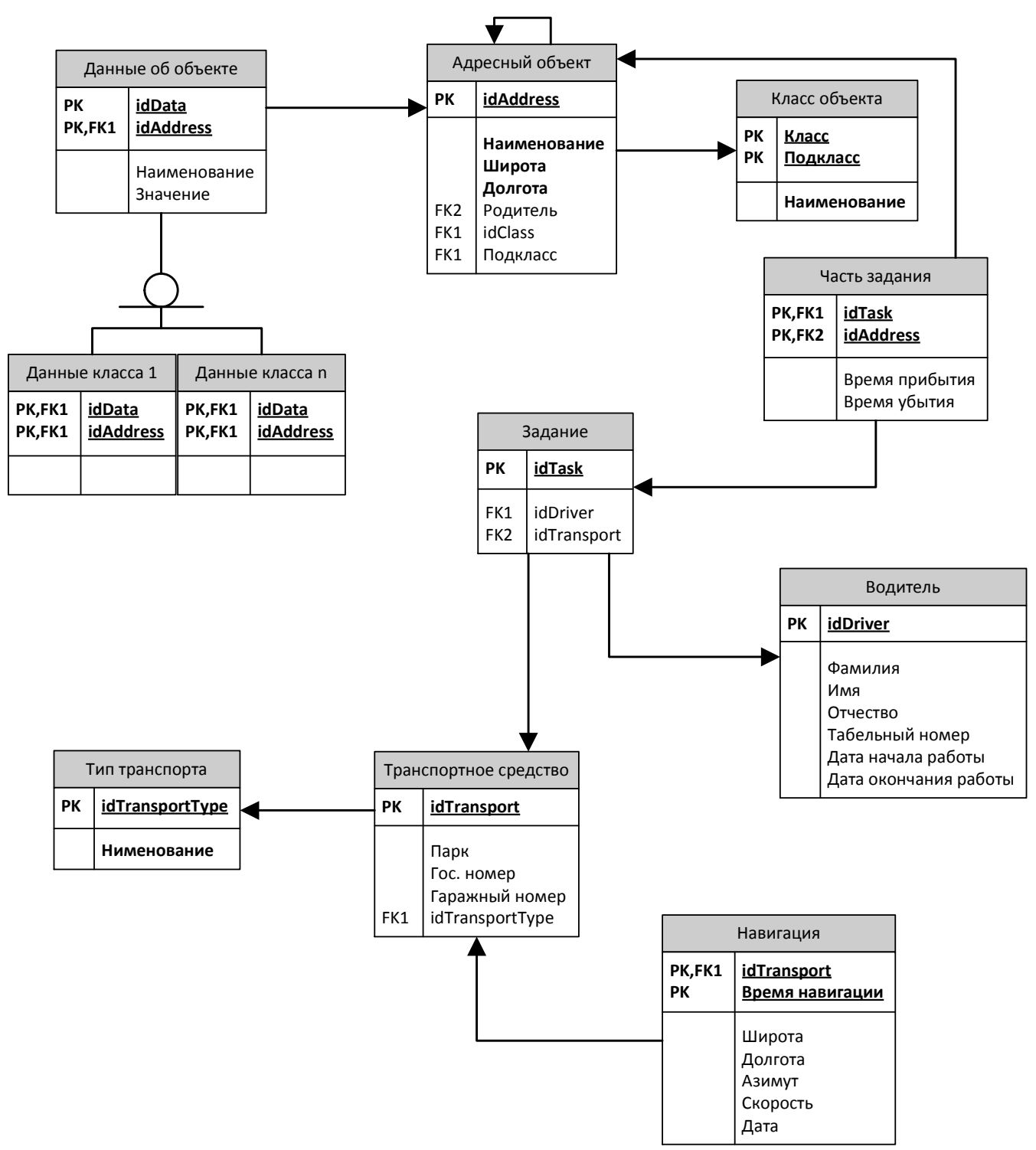




\section{Рисунок 3 - Упрощенная схема данных адресной базы}

Данная база данных должна использоваться вместо базы КП для:

- составления оперативных заданий и нарядов,

- контроля исполнения плановых заданий,

- учета и контроля движения ТС на линии,

- корректировки процесса движения ТС посредством связи с водителем,

- формирования оперативных справок и отчетных форм о состоянии ТС,

- формирования отчетных форм о выпуске ТС на линию,

- формирования отчетных форм о нарушениях в ходе работы ТС.

Порядок определения соответствия фактического выполнения транспортной работы ТС плану будет определяться за счет определения расстояния до ближайшего адресного объекта (с учетом некоторой эпсилон трубки).

Исходя из перечисленных задач, можно выделить основные функции и сформулировать приложения базы данных, а по этим приложениям можно выделить основные сущности предметной области: «Адресный объект», «Географическое местоположение», «Класс адресного объекта», «Данные об объекте», «Транспортное средство», «Водитель», «Тип транспорта». Отношения между этими сущностями представлены на диаграмме ниже, которая представляет собой подсхему БД для реализации алгоритмов сопоставления фактических и плановых показателей процесса движения. Основной сущностью является «Адресный объект».

Каждый адресный объект принадлежит какому-либо классу. Классы могут делиться на географические объекты (города, улицы), объекты инфраструктуры (объект погрузки, объект строительства, автозаправочная станция, пост ДПС, километровые столбы на трассе), а также любой другой тип классификации, необходимый для работы предприятия. Адресные объекты могу образовывать иерархию, как показано на рисунке 4. Так, объект Город может включать объекты Улица, которые в свою очередь включают объекты Дом.

Сущность «Данные об объекте» хранит информацию об адресном объекте в виде строки ключ - значение. Адресный объект может содержать большое количество метаданных, которые описывают требуемые для функционирования системы параметры. Например, это могут быть альтернативные название объекта, адрес расположения, время работы и т. д. Предполагается, что эта сущность будет расширяемой для каждого класса объектов.

Так как АСДУ является системой реального времени, многие базовые отношения находятся в третьей нормальной форме [2, 4]. Но, тем не менее, в реальную физическую схему предлагается привнести некую денормализация для того, чтобы оптимизировать работу сложных запросов базы данных, уменьшить количество связей, и повысить масштабируемость. 


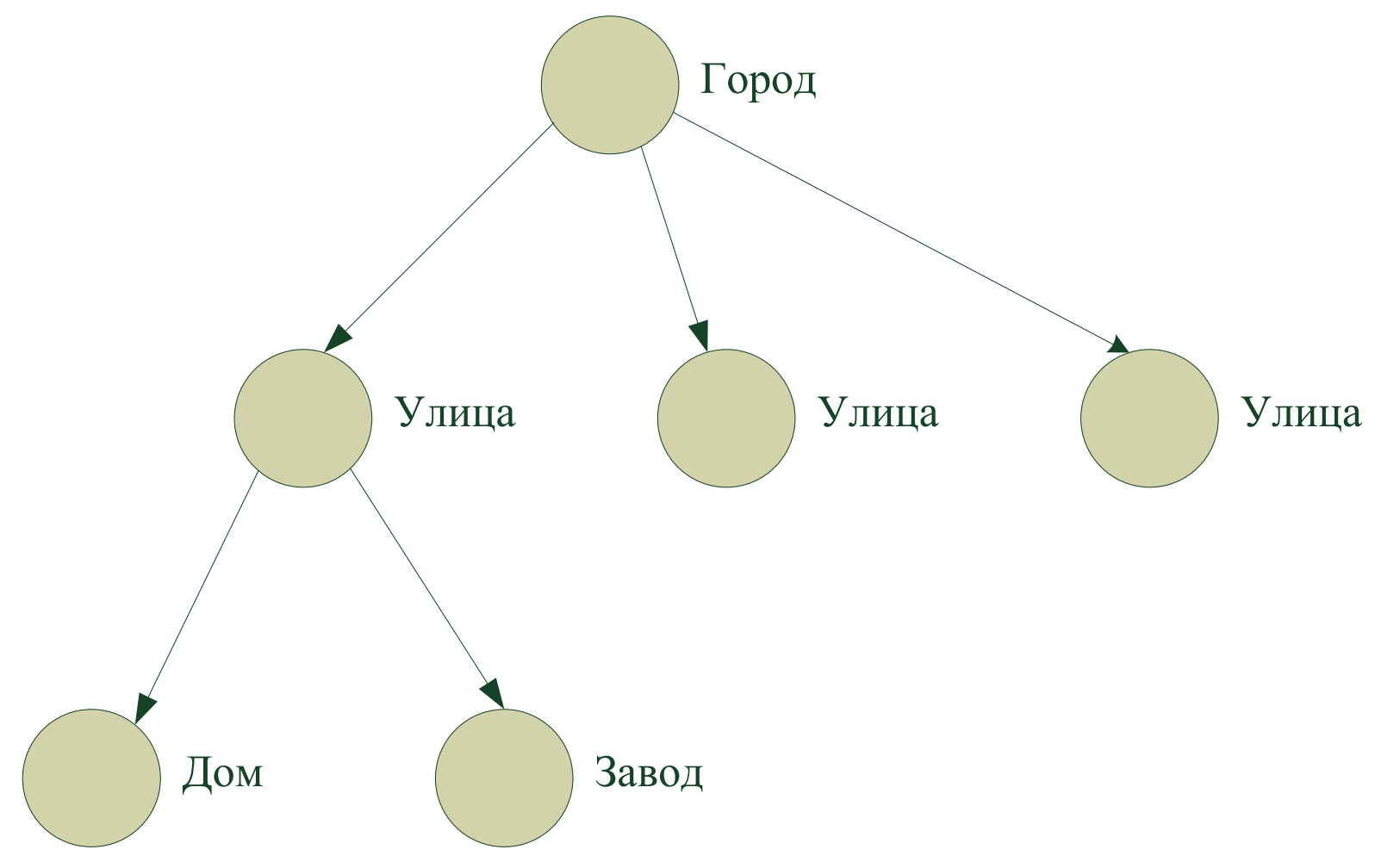

Рисунок 4 - Иерархия адресных объектов

\section{Наполнение адресной базы данных}

Отдельно стоит вопрос наполнения адресной базы. Существует несколько способов решения этой проблемы. В первую очередь необходимо предусмотреть возможность наполнения базы из открытых публичных источников.

В качестве примера такого источника можно привести открытую базу картографической информации OpenStreatMap. Данный источник содержит большую базу данных различных инфраструктурных объектов, составленную большим сообществом людей со всего мира. Благодаря этому обширному сообществу данные в системе постоянно обновляются, актуализируются и поддерживаются в точном и непротиворечивом состоянии. OpenStreatMap позволяет запросить в режиме реального времени граф интересуемого участка местности, который состоит из вершин и ребер. У каждого ребра есть обозначение, какому классу объектов оно принадлежит. Это может быть здание, перекресток или участок дороги, мост и т.п. Данные возвращаются в формате XML, поэтому легко поддаются разбору. Система может полостью автоматизировано в фоновом режиме производить выгрузку необходимых участков местности с серверов OpenStreatMap, с дальнейшим разбором и занесением в адресную базу данных.

В качестве других открытых информации предприятие может использовать коммерческие базы картографических данных, такие как ArcGIS или Резидент. Данные поставщики предоставляют свои базы данных с графами местности или точечными объектами. В случае использование таких разрозненных источников в архитектуре АСДУ необходимо предусмотреть отдельную службу интеграции, которая будет 
отвечать за преобразование различных разрозненных форматов в единый формат системы [6].

Другим способом наполнения адресной базы данных может стать автоматизированное наполнение из собственных данных о передвижении транспортных средств предприятия. В качестве примера можно рассмотреть случай, когда большое количество транспортных средств останавливается на каком-то определенном участке местности, и у всех них срабатывает датчик топлива, показывающий наполнение топливного бака, то можно с уверенностью сказать, что в этом месте находится АЗС.

Этот механизм является перспективным, но подразумевает дополнительные затраты на оборудование транспортных средств дополнительными техническими средствами, такими как датчики топлива, датчики зажигания и пр. Для обеспечения необходимого уровня точности требуется использовать методы и алгоритмы теории вероятностей и математической статистики.

Также не следует исключать возможность ручного ввода и актуализации информации. Для этого необходим программный пакет с качественным, надежным и эргономичным интерфейсом пользователя. Данный программный пакет должен на карте местности наносить необходимые адресный объекты с внесением необходимых метаданных. Но ручной ввод не должен являться основным способом ввода, а должен только дополнять описанные выше.

\section{Заключение}

Таким образом, предложен новый подход, основанный на применении адресных баз данных, который позволяет избавиться или минимизировать недостатки существующих АСДУ. Предложенный подход позволяет автоматизировать и сделать динамическим процесс построения планов исполнения транспортных работ предприятия. Разработаны схемы хранения и поступления адресных данных в АСДУ.

\section{Список информационных источников}

[1] Информационные технологии на автомобильном транспорте / В.М. Власов [и др.]; под общ. ред. В.М. Приходько; МАДИ (ГТУ). - М.: Наука, 2006. - 283 с.

[2] Исмаилов А.Р. Автоматизация контроля транспортной работы в подсистеме сбыта и реализации продукции промышленного предприятия: дис. ... канд. тех. наук 05.13.06: защищена 10.11.2010 / Исмаилов Андрей Рашидович; МАДИ (ГТУ) М., 2010 - 136 c.

[3] [Дейт, К. Дж. Введение в системы баз данных, 8-е издание / К. Дж. Дейт - М.: Издательский дом «Вильямс», 2009 - 1328 с. : ил.

[4] Польгун М.Б. Автоматизация транспортировки дорожно-строительных

[5] Ефименко Д.Б. Развитие навигационной системы диспетчерского управления грузовым транспортом (на примере нефтеперерабатывающих предприятий) / Д.Б. Ефименко, А.В. Остроух, С.А. Филатов // Автотранспортное предприятие. - 2011. - № 11. - C. 32 - 34 . 
[6] Информационные технологии на автомобильном транспорте / В.М. Власов [и др.]; под общ. ред. В.М. Приходько; МАДИ (Гос. тех. ун-т.). - М.: Наука, 2006. - 283 с.

[7] Исмаилов А.Р. Автоматизация контроля транспортной работы в подсистеме сбыта и реализации продукции промышленного предприятия: дис. ... канд. тех. наук 05.13.06: защищена 10.11.2010 / Исмаилов Андрей Рашидович; МАДИ (ГТУ) М., 2010 - $136 \mathrm{c}$.

[8] Кузнецов И.А. Особенности реализации автоматизированной информационноаналитической системы центра планирования перевозок строительных грузов / И.А. Кузнецов, А.В. Остроух // Вестник МАДИ(ГТУ). - 2008. - Вып. 1(12). - С. 9296.

[9] Куфтинова Н.Г. Процессно-ориентированный подход к автоматизации планирования и управления транспортировкой продукции предприятий промышленности / А.В. Остроух, Н.Г. Куфтинова // Вестник МАДИ - 2010. - Вып. 4(23). - C. 62-66.

[10] Куфтинова Н.Г. Разработка информационно- логической модели транспортной сети мегаполиса/ А.В. Остроух, Н.Г. Куфтинова // Бюллетень транспортной информации. - М.: Национальная ассоциация транспортников, 2013. - №1 (211). C. 23-26.

[11] Львова А.Б. Программно-технологические решения по разработке подсистем планирования заданий для заказных перевозок пассажиров при проведении олимпийских игр / Исмаилов А.Р., Львова А.Б., Остроух А.В.// Приборы и системы. Управление, контроль, диагностика. - 2013. - №11. - С. 90 - 101.

[12] Николаев А.Б. Информационные технологии в менеджменте и транспортной логистике: учебное пособие / А.Б. Николаев, А.В. Остроух. - Saint-Louis, MO, USA: Publishing House Science and Innovation Center, 2013. - 254 c. - ISBN 978-0615-67110-9.

[13] Остроух, А.В. Информационные технологии в научной и производственной деятельности [Текст] / [ред. А.В. Остроух] - М: ООО "Техполиграфцентр", 2011. 240 c. - ISBN 978-5-94385-056-1.

[14] Порфирьева С.А. Автоматизированные информационные системы на автотранспортном предприятии / С.А. Порфирьева, А.Б. Львова, К.А. Данчук, А.В. Остроух, П.С. Якунин // В мире научных открытий. - 2012. - №2.6. - С. 34-38.

[15] Польгун М.Б. Автоматизация транспортировки дорожно-строительных материалов / Автоматизация и управление в технических системах. - 2013. - № 1(3); URL: auts.esrae.ru/3-51

[16] Польгун М.Б. Концепция автоматизированной системы диспетчерского управления транспортировкой дорожно-строительных материалов / Польгун М.Б., Львова А.Б // Автоматизация и управление в технических системах. - 2013. - № 1(3); URL: auts.esrae.ru/3-55

[17] Польгун М.Б. Анализ структуры информационного обеспечения автоматизированных систем диспетчерского управления городским пассажирским транспортом // Автоматизация и управление в технических системах. - 2012. - № 1; URL: auts.esrae.ru/1-25 (дата обращения: 13.11.2013). 
[18] Польгун М. Б. Анализ моделей оперативного диспетчерского управления городским пассажирским транспортом / М. Б. Польгун, А. В. Воробьева, А. В. Остроух // Молодой ученый. - 2011. — №4. Т.3. - С. 9-13.

[19] Фаулер, М. Архитектура корпоративных программных приложений / М. Фаулер пер. с англ. - М.: Издательский дом «Вильямс», 2007. - 544 с. : ил.

[20] Ostroukh A.V., Kuftinova N.G. Automation of Planning and Management of the Transportation of Production for Food Processing Industry Enterprises. Automatic Control and Computer Sciences. 2012. Vol. 46. No. 1. pp. 41 - 48. 